\title{
Life expectation in organic brain disease
}

\section{David Jolley \& David Baxter}

The purpose of this review is to outline current knowledge on the life expectation of people suffering from organic brain disease, the techniques available for describing and comparing life expectation in populations, factors which are associated with longer and shorter life expectation, and the causes of death among patients with this condition.

\section{Survival analysis}

Death is an event or outcome which occurs to an individual, and as such is similar to other outcomes which include marriage, admission to hospital, discharge from hospital, or recovery from symptoms. These can be related in time to other (previous) events - birth, onset of illness, referral to a service, or onset of treatment. Analysis of the time between an onset and an outcome tells us something of the experience of an individual, or of groups of individuals who may be considered together because they share particular characteristics (they might be suffering from the same illness or receiving a common treatment regime).

The statistical techniques used to analyse these experiences are described as survival analyses. The usefulness of such analyses are determined by the validity and reliability of the basic data used. Some onset data are easily determined, and should be both accurate and reliable; for example, date of birth, or date of admission to hospital. Other onset data, which are appealing because of their potential link to biological events, are less easy to determine with accuracy or certainty; for example, onset of illness or onset of symptoms. Similarly, death or discharge from hospital are hard, reliable outcome events, whereas 'recovery from symptoms' is less easy to determine.

Follow-up studies present a number of difficulties in analysis. Some patients will have reached the event of interest (death in studies of survival/mortality) while others have not. The period over which individuals have been followed usually varies and some patients will have been lost from the study, perhaps because they have moved away, withdrawn from the study, or become non-compliant with the treatment of interest. Data relating to such individuals can be included in analyses of survival/mortality but needs to be 'censored' so that they contribute only the time/experience during which they satisfy inclusion criteria of the analysis.

Simple analyses of survival/mortality can be presented as: the proportion of patients reaching the end-point (death) during a predetermined period of follow-up; the median survival time for the cohort using life tables or Kaplan-Meier curves; or death rates per unit of time in follow-up (e.g. person-years at risk) (Altman, 1992).

Having determined the survival experience of a group of individuals, one is usually interested in how this compares with a reference population (e.g. a non-exposed group, a disease-free group, or a standard treatment group). Survival curves can be compared using the log rank test, which tests the null hypothesis that the groups being compared are from the same population. Alternatively, a measure of difference between the survival experiences of two populations can be

David Jolley is Professor of Old Age Psychiatry, University of Wolverhampton and Wolverhampton Health Care NHS Trust (Penn Hospital, Penn Road, Wolverhampton, West Midlands WV4 5HN). Recently, he moved to Wolverhampton to re-establish mental health and elderly care services to a community model, in which to continue his teaching and research ideas developed during 20 years in Manchester. David Baxter is Senior Lecturer in Public Health Medicine at Manchester University, with research interests in the epidemiology of various disorders, including mental health problems. 
obtained by calculating the 'hazard ratio' (denoted ' $R$ '), which is compute $A$ from the observed number of events (deaths) compared with the number of events expected if the null hypothesis (that the two groups are from the same population) were true.

$$
\mathrm{R}=\frac{\mathrm{O}_{1}}{\mathrm{E}_{1}} \times \frac{\mathrm{E}_{2}}{\mathrm{O}_{2}}
$$

Confidence intervals can be calculated for individual survival probabilities and for the difference between survival probabilities for two groups.

\section{Mortality in mentally ill populations}

Although mental illnesses are not usually looked on as causative of early death in the same way as conditions such as cancer, heart disease or acute infections, it has been known for many years that survival among psychiatric patients is shorter than for the general population of similar age and in the same calendar period.

Using the Norwegian Psychiatric Case Register, Odegard demonstrated that mortality rates among the asylum populations at the turn of the century were five times those of the general population (Odegard, 1953). Malzeberg reported similarly increased death rates among patients admitted to New York mental hospitals during the period 1929-1931, and undertook a longitudinal study of patients admitted to these hospitals between 1943 and 1944, which demonstrated an increased risk of death for all diagnostic groups over a four-year follow-up period. The relative risk was highest for patients suffering from organic brain syndromes (Malzeberg, 1952). Most of the excess deaths within mental hospitals were due to infectious diseases, including tuberculosis, and may have been related to impaired nutrition and the poor, overcrowded conditions under which 'inmates' were kept (Digby, 1983).

Death rates among the general population of England and other European countries have fallen progressively through the 20th century; by 1970 death rates among women had fallen to half the level in 1900 and death rates among men had fallen by one-third in the same period (Cartwright et al, 1973). Improvements in life expectation were even greater among male patients admitted to Norwegian mental hospitals, so that their excess mortality ratio fell from $5.1: 1$ to $2.4: 1$. For female patients, however, the improvement in mortality was less, with the excess mortality falling from
$4.5: 1$ to $3.5: 1$ (Sangstad \& Odegard, 1979). Similar reductions in death rates and lowered excess mortality ratios were achieved in mental hospitals in the rest of Europe and North America, probably because of improved conditions of hygiene, heating and food.

Death rates among psychiatric in-patients continue to exceed those of the general population by factors of between two and three. Many unexpected deaths occur to young male patients and these are most often due to suicide or other non-accidental injuries. Advances in treatment methods and alterations in service styles in psychiatric practice have meant that many patients are now treated within their natural community. Thus, studies of survival/death rates among the mentally ill must utilise techniques which allow patients to be followed over periods of time through different modes of care. This can be achieved by a service-based register (Rorsman, 1974), record-linkage (Black et al, 1985a,b,c), or by creating a short-term register to follow a limited cohort of patients over a short time (Martin et al, 1985).

Studies of out-patients demonstrate that death rates are higher than in the general population, relative risk of death being more markedly raised among younger patients but remaining elevated into later life (Odegard, 1953; Rorsman, 1974; Black et al, 1985a,b,c; Zilber et al, 1989; Wood et al, 1991). Reduced survival is found within all the major psychiatric diagnostic groupings: schizophrenia (Zilber et al, 1989; Baxter, 1993), mood disorder (Black et al, 1985a,b,c; Zilber et al, 1989; Baxter, 1993), personality disorder (Blacket al, 1985; Zilber et al, 1989; Baxter, 1993), neurosis (Black et al, $1985 a, b, c ;$ Baxter, 1993) and organic brain disease.

\section{Mortality in organic brain disease}

The diagnosis of organic brain disease is made on clinical grounds at a 'syndromal' level. That is, it brings together a number of conditions which produce similar alterations in mental state: disorders of cognition, impaired memory, difficulty with registration and recall of information, poor concentration and limited tolerance. There may be disorientation in time, place or person and perseveration of thoughts, acts or feelings. Emotional control may be impaired and there may be other abnormalities of mood, psychotic phenomena or evidence of focal brain disorder (Lishman, 1978). It is an acquired condition rather 
than one present from birth and is associated with damage to brain substrate from trauma, infection, neoplasia, pressure or degenerative disorder. Similar changes may be produced by alterations in the bodily milieu due to failure of the internal homeostatic mechanisms.

In population studies the most common underlying causes of organic brain disease are the degenerative dementias such as Alzheimer's disease, multi-infarct (vascular) dementia and Lewy body disease. Yet many studies are neither designed nor equipped to penetrate beneath the syndromal level of classification, and findings are expressed at this level. As more refined clinical and investigatory tools have become available, recent studies have restricted their interest to specific conditions (often Alzheimer's disease).

Death rates among patients with organic brain disease are raised compared with those of the general population of the same age. Sir Martin Roth's classic papers (1955), which plotted the outcome for elderly patients admitted to Graylingwell Hospital, demonstrated that $55 \%$ of patients admitted with organic brain disease died within six months and $80 \%$ were dead within two years. In comparison, only $13 \%$ of patients suffering from 'functional' disorders had died within six months, and $40 \%$ within two years.

Although institution-based, this work generated interest in the survival/mortality of older patients and has been followed by studies in the community, in domiciliary services and within nursing homes as well as hospitals. Clinicians, patients, relatives, service planners and legal advocates want to know the chances of survival for individual patients or groups of patients through specified periods of time, and average life expectation. They are interested in the modifying effects of gender, duration of illness, severity or stage of the illness, the presence of particular symptoms or of other pathology, the use of medication, and care within particular regimes (Laupaciset al, 1994). Published reports usually reflect the natural history of the illness within a given context, for there are few opportunities for controlled, randomised experiments. The best-designed studies follow a welldefined, representative cohort of individuals to a point of follow-up, and comparisons are made with a suitable control population. For example, Black et al (1985a) reported on 5412 patients admitted to University of Iowa Psychiatric Hospital between 1 January 1972 and 31 December 1981. Five hundred and forty-three ( $281 \mathrm{men}, 262$ women) were suffering from organic brain disease (ICD-9 codes 290-294). One hundred and fiftyeight (96 men, 62 women) were suffering from organic brain disease related to excessive use of alcohol. The age spectrum of these patients was mainly middle age: mean age for men 47.4 years; for women 51.0 years. The average period of follow-up was 4.5 years. The estimated standardised mortality rates (SMRs) for both male (1.75) and female (2.1) patients were significantly raised at the $P<0.001$ level. SMRs were greatest among patients aged under 40 years (male 8.23, female 15.63) and fell to below statistical significance in those aged over 69 years (male 1.05, female 1.12). Death rates were particularly high during the three months after admission, but remained significantly elevated throughout the 24 months after first service contact. Expected deaths were computed using the mortality rates from the Iowa population.

Magnusson (1989) addressed a very different population of people with organic brain disorder in late life. He assessed 876 people out of 1049 Icelanders in their eighties and from whom 220 cases of dementia were identified. Few of these were related to alcohol excess, most being classified as due to Alzheimer's disease or multiinfarct dementia. SMRs were increased significantly for both men (2.46) and women (2.29) with death rates of $0.1-0.3 / 100$ per annum in males and $0.2 / 100$ per annum in females. In a study of patients with similar characteristics drawn from the population of Lienden in Holland, Heeren et al (1992) found an SMR of 1.9 (95\% CI 1.7-2.2). The Inverurie study (Eagles et al, 1990) identified villagers aged over 65 years with cognitive impairment on the mental status questionnaire (not claiming equivalence to organic brain disease or dementia, but probably not much different) and found a relative risk of death during 36 months of 3.5 (CI 2.37-5.17) compared with the cognitively preserved controls. Burns et al (1991) calculated the SMR for their cohort of 178 subjects, suffering from Alzheimer's disease and in touch with the Camberwell Psychogeriatric Service, to be 3.5, and found that $47 \%$ of patients died within three years of referral to the service.

Thus, there is consistent evidence of raised death rates among patients with organic brain disease, whether they are known to specialist services as in-patients or out-patients or identified within the community. Yet Christie and co-workers (Christie, 1982, 1985; Christie \& Train, 1984; Wood et al, 1991) and Blessed \& Wilson (1982) drew attention to falling death rates among patients admitted to psychiatric care. Only $32 \%$ of admissions died within six months in Newcastle in the 1970s (25\% in Crichton Royal at the same time), compared with Roth's 1950s figure of 55\%. Roth's two-year (1950s) death rate of $80 \%$ contrasted with $68 \%$ in Newcastle and 55\% in Crichton Royal in the 1970s. Patients with dementia admitted to Crichton Royal 
Hospital in the 1970 s were likely to survive longer, by a factor of 1.5-2.0, than similar patients in the 1950s. The Office of Health Economics (1979) drew attention to a similar phenomenon in its influential pamphlet, which drew on the Lundby studies interpreted by Gruenberg \& Hagnell (1978), and reflected increasing survival among successive cohorts of people suffering from dementia in the community. A striking graphical representation of the figures (using a log scale) encouraged the idea that survival among people with dementia was improving ahead of that of the general population and added fuel to anxieties that well-motivated improvements in services were embarrassing our capacity to fund the additional life-years in states of dependency which they achieved. This reaction failed to acknowledge that SMRs continue to be high in dementia and better services continue to enable people to cope longer before needing the most expensive (institutional) forms of care (Thompson \& Eastwood, 1981).

\section{Factors associated with increased mortality (Box 1)}

Age

All studies concur that later age of onset is associated with shorter life expectation, but that SMRs are markedly higher in patients with a younger age of onset.

\section{Gender}

Kay (1962) found the SMR for men was raised by a factor of four, but for women by only three, and this increased risk in males has been confirmed by others (e.g. Barclay et al, 1985b).

\section{Family history}

Knesevich et al (1985) found that cases with a family history of dementia lived longer than those without such a history.

\section{Marital status}

Ryan (1992) found that patients suffering from dementia died before their (non-demented) spouses, but marital status did not influence survival among patients referred to Salford psychiatric services (Jolley, 1996).

\section{Social class}

Magnusson (1989) found longer survival in social class I.

\section{Accommodation}

Magnusson (1989) demonstrated similar life expectation among patients living at home and in residential or nursing homes, although Eagles et al (1990) suggested that care in a residential home might be protective and increase survival times.

\section{Clinical features}

Severity of cognitive impairment is directly related to reduced survival in some studies (Burns et al, 1991). Others, however, have found no relationship between measures of severity and longevity (Magnusson, 1989; Heeren et al, 1992). Aphasia (Faber-Langendoen et al, 1988) and parietal lobe dysfunction (McDonald, 1969; Burns et al, 1991) carry a poor prognosis. Depressive mood (Naguib \& Levy, 1982a; Burns et al, 1991) is, however, associated with increased survival among patients known to psychiatrists.

\section{Dementia spectrum diagnosis}

There are suggestions that Alzheimer's disease brings death forwards less than multi-infarct dementia, but the picture is variable (Martin et al, 1987). Misidentification syndrome is associated with longer life among patients with Alzheimer's disease in contact with psychiatric services (Burns et al, 1991). Psychotic features such as delusions or hallucinations are associated with shorter survival (Stern, 1987). Behavioural abnormalities at the time of presentation or assessment (Barclay et al, 1985b; Diesfeldt et al, 1986; Moran et al, 1990) are associated with reduced survival. Evidence of physical disability, including reduced mobility, is strongly associated with earlier death (Diesfeldt et al, 1986; Ballinger et al, 1988). Concomitant physical illness (Burns et al, 1991; Pietier et al, 1992) predicts earlier death.

\section{Nutritional status}

Gale et al (1996) have demonstrated an association between vitamin $C$ intake and both the risk of developing cognitive impairment and the rate of death among those who become impaired. 
Box 1. Factors associated with mortality

Usually associated with shorter survival

Older age

Male gender

Severe cognitive impairment

Parietal lobe dysfunction

Dysphasia

Psychotic symptoms

Behavioural abnormalities

Physical incapacity

Physical illness

Poor nutrition

Usually associated with longer survival

Younger age

Female gender

Family history

Mild cognitive impairment

Depressed mood

Misidentification syndrome

\section{Computed tomography findings}

Naguib \& Levy $(1982 a, b)$ and Colgan (1985) found attenuation densities in the parietal, occipital and left thalamic areas associated with reduced survival. Burns et al (1991) demonstrated that raised atrophy scores predicted earlier death.

\section{Cause of death}

David Kay (1962), following the system of Alstrom (1942), developed the concept of death from 'nonspecific' causes (old age, bronchopneumonia, diseases of the circulatory system) and 'specific' causes (all other diseases). In Kay's follow-up study, patients with organic brain disease were three times more likely to die from bronchopneumonia than patients with other psychiatric diagnoses. Similar findings have been reported by many subsequent workers (e.g. Magnusson, 1989; Black \& Jolley, 1990; Burns et al, 1990; Ryan, 1993). Puxty et al (1983) had found bronchopneumonia to be the most common immediate cause of death among older people dying after admission to acute medical wards. Nevertheless, the excess of deaths attributed to this 'non-specific' cause within organic brain disease is probably real: Sangstad \& Odegard (1979) estimated this mode of death to be 10 times as common in organic brain disease than in other people; Magnusson (1989) found it to be five times as common in organic brain disease, even among very old people, and Peck et al (1978) found it to be twice as common in organic brain disease within a very elderly group of people in residential care.

Relatively little attention has been given to excess of other 'specific' causes of death. Burns et al (1990) found a raised rate of pulmonary embolism in the 84 patients from their series who had died by the time of report, and Burns (1992) drew attention to three other studies noting this phenomenon. Chandra et al (1986) reviewed nearly two million death certificates in the USA and found that where dementia was mentioned on the certificate, excess deaths attributable to specific causes included injuries (especially fracture of the femur) and diseases of the nervous system, including Parkinsonism, and nutritional problems. A limitation of many studies is that few patients have come to post-mortem. Thus, diagnoses are dependent on the acumen of the clinician and there may be differences between clinical diagnosis and post-mortem findings of the order of $40 \%$ (Cameron \& McGoogan, 1981). Tench et al (1992), however, found old age psychiatrists were no less accurate than other hospital specialists in diagnosing physical illnesses among their patients.

\section{Interpretation}

Explanations for the increased death rates and the pattern of causes of death among patients with organic brain disease rests on three major themes:

(a) This is essentially a degenerative disease of the nervous system and is related to other neurological conditions. It is associated with progressive weakness, liability to falls and injuries, immobility and vulnerability to inanition, infection and death. This explanation fits easily with the pattern of excess deaths described in all series reported, including deaths by pulmonary embolism, fractured femur, or other neurological illness, which are the only specific causes regularly reported in excess.

(b) Metabolic abnormalities might contribute to wasting in terminal dementia. This continues to be a theory worth further investigation, although little evidence supports its validity and it cannot account for the similar increase in death rates across a number of specific diagnoses (Burns et al, 1989). 
(c) Malabsorption of particular vitamins has been demonstrated in dementia of late onset, but more generalised problems of malabsorption as contributors to aetiology have not been confirmed (Abalan, 1984).

\section{Mode of death}

Few studies have addressed the mode of death among patients dying with organic brain disease, but Black \& Jolley $(1990,1991)$ pointed out that many patients who die in hospital after suffering from the disease for many years, enter a period of 'pre-death' or 'protracted dying' in which they are clearly disturbed and distressed. They benefit from positive approaches to their care in this phase of life in the same way as people suffering from cancer, whose care has been improved by approaches fostered by the hospice movement.

\section{Conclusions}

Death rates among patients with organic brain disease are raised compared with the general population and are higher than for patients with other psychiatric disorders. Nevertheless, it is clear that patients with organic brain disease now survive longer than similar patients did 40 years ago. Features associated with longer and shorter survival can help the clinician and family in preparing for the future. These characteristics need to be taken into account when evaluating the effects of alternative strategies of care, including the prospect of treatment with anti-dementia medication.

Excess deaths are predominantly attributed to 'non-specific' causes, especially bronchopneumonia. In some studies extra 'specific' causes of death have been attributed to: injuries (consequent upon falls), pulmonary embolism, diseases of the nervous system, and nutritional problems. The significance of these may be better evaluated if more patients can come to post-mortem examination.

\section{References}

Abalan, P. (1984) Alzheimer's disease and malnutrition: a new etiological hypothesis. Medical Hypotheses, 15, 385.

Alstrom, C. (1942) Mortality in mental hospitals with especial regard to tuberculosis. Acta Psychiatrica Scandinavica Supplementum, 24.
Altman, D. G. (1992) Practical Statistics for Medical Research. London: Chapman and Hall.

Ballinger, B., McHarg, A., MacLennan, W., et al (1988) Dementia, psychiatric symptoms and immobility: a one year follow-up. International Journal of Geriatric Psychiatry, 3, 125-129.

Barclay, L. L., Zemcov, A., Blass, J. P., et al (1985a) Survival in Alzheimer's disease and vascular dementias. Neurology, 35, 834-840.

- - - - et al $(1985 b)$ Factors associated with duration of survival in Alzheimer's disease. Biological Psychiatry, 20, 68-93.

Baxter, D. (1993) Mortality studies in individuals enrolled with the S Psychiatric Case Register. PhD thesis, Manchester University.

Black, D. \& Jolley, D. (1990) Slow euthanasia? The deaths of psychogeriatric patients. British Medical Journal, 300, 13211323.

— \& - (1991) Deaths in psychiatric care. International Journal of Geriatric Psychiatry, 6, 489-495.

-, Warrack, G. \& Winokur, G. (1985a) Excess mortality among psychiatric patients. Journal of the American Medical Association, 253, 58-61.

- _ \& - (1985b) The Iowa record-linkage study. 1: Suicides and accidental deaths among psychiatric patients. Archives of General Psychiatry, 42, 71-75.

- _ _ \& - (1985c) The Iowa record-linkage study. II: Excess mortality among patients with organic mental disorders. Archives of General Psychiatry, 42, 78-81.

Blessed, G. \& Wilson, I. D. (1982) The contemporary natural history of mental disorder in old age. British Journal of Psychiatry, 141, 59-67.

Burns, A. (1992) Cause of death in dementia. International Journal of Geriatric Psychiatry, 7, 461-464.

-, Marsh, A. \& Bender, D. A. (1989) Dietary intake and anthropometric and biochemical indices of malnutrition in elderly demented patients and non-demented subjects. Psychological Medicine, 19, 383-391.

-, Jacoby, R., Luthbert, P., et al (1990) Cause of death in Alzheimer's disease. Age and Ageing, 19, 341-344.

-, Lewis, G., Jacoby, R., et al (1991) Factors affecting survival in Alzheimer's disease. Psychological Medicine, 21, 363-370.

Cameron, H. \& McGoogan, E. (1981) A prospective study of 1152 hospital autopsies. 2: analysis of inaccuracies in clinical diagnosis and their significance. Journal of Pathology, 133, 285300.

Cartwright, A., Anderson, J. \& Hockey, L. (1973) Life Before Death. Social Studies in Medical Care. London: Routledge and Kegan Paul.

Chandra, V., Bharucha, N. E. \& Schoenberg, B. S. (1986) Conditions associated with Alzheimer's disease at death: a case-control study. Neurology, 36, 209-211.

Christie, A. B. (1982) Changing patterns in mental illness in the elderly. British Journal of Psychiatry, 140, 154-159.

- (1985) Survival in dementia: a review. In Recent Advances in Psychogeriatrics, vol 1 (ed. T. Arie), pp. 33-44. Edinburgh: Churchill Livingstone.

- \& Train, J. D. (1984) Changes in the pattern of care for the demented. British Journal of Psychiatry, 144, 9-15.

Colgan, J. (1985) Regional density and survival in senile dementia. An interim report on a prospective computed tomographic study. British Journal of Psychiatry, 147, 63-66.

Diesfeldt, H. F., van Houte, L. R. \& Moerkens, R. M. (1986) Duration of survival in senile dementia. Acta Psychiatrica Scandinavica, 73, 366-371.

Digby, A. (1983) Changes in the asylum: the case of York 17771815. Economic History Review, 36, 218-239.

Eagles, J. M., Beattie, J. A. G., Restall, D. B., et al (1990) Relation between cognitive impairment and early death in the elderly. British Medical Journal, 300, 339-340.

Faber-Langendoen, K., Morris, K., Knesevich, J., et al (1988) Aphasia in senile dementia of the Alzheimer type. Annals of Neurology, 23, 365-370.

Gale, C. R., Martyn, C. N., Winter, P. D., et al (1996) Cognitive impairment and mortality in a cohort of elderly. British Medical Journal, 312, 608-611.

Giel, R., Dijk, S. \& Van Weerden-Dijkstra, J. R. (1978) Mortality in the long-stay population of all Dutch mental hospitals. Acta Psychiatrica Scandinavica, 57, 361-368. 
Gruenberg, E. M. \& Hagnell, O. (1978) In Society, Stress and Disease: Ageing and Old Age (eds L. Levi \& A. R. Kagan). London: Oxford University Press.

Heeren, T., van Hemert, A. \& Rooymans, H. (1992) A community based study of survival in dementia. Acta Psychiatrica Scandinavica, 85, 415-418.

Jolley, D. (1996) Mortality in Patients with Organic Brain Disorder Enrolled on the Salford Psychiatric Case Register. MSc thesis, Manchester University.

Kay, D. W. K. (1962) Outcome and cause of death in mental disorders of old age. Acta Psychiatrica Scandinavica, 38, 249-276.

Knesevich, J., Toro, F., Morris, J., et al (1985) Aphasia, family history and the longitudinal course of senile dementia of the Alzheimer type. Psychiatry Research, 14, 255-264.

Laupacis, A., Wells, G., Richardson, W. S., et al (1994) Users' guide to the medical literature. V: How to use an article about prognosis. Journal of the American Medical Association, 273, 113125 .

Lishman, A. (1978) Organic Psychiatry. Oxford: Blackwell Scientific.

McDonald, C. (1969) Clinical heterogeneity in senile dementia. British Journal of Psychiatry, 115, 267-271.

Magnusson, H. (1989) Mental health of octogenerians in Iceland. An epidemiological study. Acta Psychiatrica Scandinavica Supplementum, 349, 1-112.

Malzeberg, B. (1952) Rates of discharge and rates of mortality among first admissions to New York civil state hospitals. Mental Hygiene, 36, 104-120.

Martin, D., Miller, J., Kapoor, W., et al (1987) A controlled study of survival with dementia. Archives of Neurology, 44, 11221126.

Martin, R. L., Cloninger, R., Guze, S. B., et al (1985) Mortality in a follow up of 500 psychiatric outpatients. Archives of General Psychiatry, 42, 47-54.

Moran, S. M., Cockram, L. L., Walker, B., et al (1990) Prediction of survival by the Clifton Assessment Procedure for the Elderly (CAPE). British Journal of Clinical Psychology, 29, 225226.

Naguib, M. \& Levy, R. (1982a) Prediction of outcome in senile dementia - a computed tomography study. British Journal of Psychiatry, 140, 263-267.

- \& — (1982b) CT scanning in senile dementia. A follow-up of survivors. British Journal of Psychiatry, 141, 618-620.

Odegard, O. (1953) The excess mortality of the insane. Acta Psychiatrica et Neurologica Scandinavica, 27, 353-367.

Office of Health Economics (1979) Dementia in Old Age. London: OHE.

Peck, A., Wolloch, L. \& Rodstein, M. (1978) Mortality of the aged with chronic brain syndrome: further observations in a 5 year study. Journal of the American Geriatrics Society, 16, 170-176.

Pietier, T., van Dijk, H. J., van de Sande, R., et al (1992) The nature of excess mortality in nursing home patients with dementia. Journal of Gerontology: Medical Sciences, 47, M28-M34.

Puxty, J., Horan, M. \& Fox, R. (1983) Necropsies in the elderly. Lancet, $i, 1262-1264$

Rorsman, B. ( 1974 ) Mortality among psychiatric patients. Acta Psychiatrica Scandinavica, 50, 354-375.

Roth, M. (1955) The natural history of mental disorders in old age. Journal of Mental Science, 101, 281-301.

Ryan, D. H. (1992) Is there a desolation effect after dementia? A comparison study of mortality rates in spouses of dementia patients after admission and bereavement. International Journal of Geriatric Psychiatry, 7, 331-339.

- (1993) Death in dementia: a study of causes of death in dementia patients and their spouses. Journal of Geriatric Psychiatry, 7, 465-472.

Sangstad, L. \& Odegard, O. (1979) Mortality in Norwegian mental hospitals 1950-1974. Acta Psychiatrica Scandinavica, $59,431-447$.

Tench, D., Benbow, S. M. \& Benbow, E. W. (1992) Do old age psychiatrists miss physical illness? International Journal of Geriatric Psychiatry, 7, 713-718.

Thompson, E. G. \& Eastwood, M. R. (1981) Survivorship and senile dementia. Age and Ageing, 10, 29-32.

Wood, E., Whitfield, E. \& Christie,A. (1991) Changes in survival in demented hospital inpatients 1957-1987. International Journal of Geriatric Psychiatry, 6, 523-528.
Zilber, N., Schufman, N. \& Lerner, Y. (1989) Mortality among psychiatric patients. Acta Psychiatrica Scandinavica, 79, 248-256.

\section{Multiple choice questions}

1. In survival analyses:

a data relating to individuals who have become 'lost to follow-up' have to be discarded

b findings can be presented as the proportion of patients who have died before a predetermined review date

c findings can be presented as death rate per unit time of follow-up

d the hazard ratio can be used to compare survival curves

e estimates of survival from onset of illness are more reliable than estimates from date of referral to a service.

2. Death rates among the mentally ill:

a are elevated in all the major psychoses

b are elevated only among in-patients

c have fallen more rapidly than death rates in the general population during this century

d are higher in younger than in older patients

e are highest in organic brain disease.

3. Mortality in organic brain disease:

a has remained stable during this century

$\mathrm{b}$ is raised in all age bands over 65 years

$c$ is higher during the second year of contact with services than in the first year

d more than $50 \%$ of patients admitted to psychiatric wards during the 1970 s were still alive two years later

e is raised whatever the underlying organic pathology is found to be.

4. Life expectation in organic brain disease:

$a$ is reduced equally in men and women

b is consistently found to be reduced in a direct relationship with severity of cognitive impairment

c is longer in patients with depressive symptoms at the time of presentation to services

d is longer in patients with psychotic symptoms

$e$ is reduced in patients with evidence of parietal lobe damage.

5. Cause of death in organic brain disease:

a is usually determined by post-mortem findings

b is less accurately reflected by death certificates from psychogeriaticians than 
cause of death certified by other hospital disciplines

c is most commonly due to bronchopneumonia

d pulmonary embolism and fractures have been found in excess in some series

e is simply a reflection of differing patterns of death among very old people.

\begin{tabular}{|c|c|c|c|c|}
\hline \multicolumn{5}{|c|}{ MCO answers } \\
\hline 1 & 2 & 3 & 4 & 5 \\
\hline a $F$ & a $T$ & a $F$ & a $F$ & a $F$ \\
\hline b $\mathrm{T}$ & b F & b $\mathrm{T}$ & b F & b $F$ \\
\hline c $T$ & c $\mathrm{F}$ & c $\mathrm{F}$ & c $T$ & c $\mathrm{T}$ \\
\hline d F & d F & d F & d F & d F \\
\hline e $F$ & e $T$ & e $T$ & e $T$ & e $\mathrm{T}$ \\
\hline
\end{tabular}
$\mathrm{F}$
a $\mathrm{T}$
a $\mathrm{F}$
a $\mathrm{F}$
b $T$ b $F$
b $F$
c $T$ c $F$
e $F$ e $T$
e $\mathrm{T}$
e $T$
e $T$ 